18. Lindner.-Arch. f. Augenheilk., Vol. LXXVIII, p. 245, 1911 ; Ibid., Vol. LXXXIV, p. 1, 1913; Klin. Monats. f. Augenheilk., Vol. LXXVII, p. 555, 1926; Zeitschr. f. Augenheilk., Vol. LVII, p. 508, 1926.

19. Aust. -Arch. f. Augenheilk., Vol. CXXIII, p. 93, 1929.

20. Taboriski.-Arch. f. Ophthal., Vol. CXXIV, p. 455, 1930.

21. Bengston.-Amer. Jl. of Ophthal., p. 637, 1929.

22. Gifford and Lazar.-Arch. of Ophthal., p. 468, October, 1930.

23. von Szily.-Klin. Monats. f. Augenheilk., Vol. XLIX, p. 265, 1911.

24. Solovieff.-Arch. Institut Pasteur de l'Afrique du Nord, Vol. I, p. 388, 1921.

25. Noguchi.-Jour. Exper. Med., Suppl. No. 2, August, 1928.

26. Finnoff and Thygeson.-Amer. Jl. of Ophthal., Vol. XII, p. 651, 1929, and address at Amer. Med. Assoc. Annual Meeting, 1930.

27. Kendall. - Personal communication by Thygeson.

28. Tilden and Tyler.-Science, Vol. LXXI, No. 1833, p. 186, 1930.

29. Olitsky.-Science, p. 263, 1930.

30. Addario.-Revue du Trach., p. 14, January, 1931.

31. Stepanowa and Azarowa.-Jl. Microbiol., Vol. VIII, p. 180, 1929 (abst. Arch. of Ophthal., Vol. II, p. 357, 1929.)

32. Weiss.-Personal communication.

33. Lumbroso.-Compte-rendu Acad. Science, Vol. CXC, p. 1026, 1930.

34. Bietti.-Boll. d'Ocul., 9, 10, p. 1170 (abst. Klin. Monats. f. Augenheilk., Vol. LXXXV, p. 734, 1930.

35. Lindner and Rieger.-Zeitschr. f. Augenheilk., Band LXXII, Heft 1/2, p. $116,1,930$.

36. Bengston.-Personal communication by Dr. Proctor.

37. Morax.-Revue du Trach., Vol. VII, p. 2, 1930.

38. Brückner.-Oftal. Sbornik, Vol. III, p. 1, 1929.

39. Wilson.-Bull. Ophthal. Soc. of Egypt, p. 36, 1928.

40. Weiss.-Personal communication.

41. Howard.-Personal communication by Dr. Proctor.

42. Olitsky.-Revue du Trach., p. 173, 1930.

43. Lindner.-Arch. f. Ophthal., Vol. CXXII, p. 391, 1929.

\title{
THE OCULAR COMPLICATIONS OF ACNE ROSACEA
}

\author{
BY \\ J. H. Doggart \\ MOORFIELDS RESEARCH SCHOLAR

\section{I.-Abstract of the Literature}

Aetiology of Acne Rosacea.-The majority of sufferers from acne rosacea are women between the ages of 30 and 60 years. In many standard text-books the women are said to be five or more times as numerous as the men, but in Triebenstein's series of $2 \pi 4$ patients, and in Rulison's 135, one-third were males. Triebenstein has seen the disease in infants less than three years old, but it is certainly unusual for anyone to be affected before the age of 20 . The causation is not definitely known, although many writers on this subject have agreed in suspecting tea, alcohol, and dysmenorrhoea. Recent researches by Ryle and Barber showed that the average amount of gastric hydrochloric acid secreted by acne 
rosacea patients was below normal. Brown confirmed these conclusions. He found that the gastric juice of 50 sufferers from this disease contained a much lower average percentage of hydrochloric acid than did control juice taken from 50 victims of various other skin diseases. Further confirmation was provided by Sequeira, Grintschar and Eastwood. The problem is, however, complicated by Brown's own finding that some of the worst individual cases gave normal hydrochloric-acid-secretion ' figures. Rulison and Eastwood both considered that low blood-pressure plays its part in the production of the disease. Eastwood also blames focal sepsis, and excessive ingestion of carbohydrates. In Piriès' experience Jewesses are particularly susceptible.

General Description of the Disease.-Acne rosacea begins with transient flushing of the face, recurring at variable intervals. The onset is so gradual that for many years there may, in the intervals between attacks, be no evidence to warrant a diagnosis. The incidence of the attacks may be seasonal. After repeated flushings the affected skin-vessels remain permanently dilated, so as to cause a hyperplasia of the sebaceous glands. This hyperplasia is manifested by the formation of papules, which occasionally suppurate. Sebaceous hyperplasia on the nose, together with proliferative changes in the dermal connective tissue of this region, frequently end in producing the condition known as rhinophyma, to which men are more liable than women. Since the condition of the skin of the face is attended by little or no pain, the evil effects of the disease are, in the absence of ocular complications, mainly cosmetic - a fact which may explain why the preponderance of female cases is less overwhelming than has sometimes been supposed. Ocular complications are absent in the great majority of cases.

Ocular Complications.-Since the original observations of von Arlt in 1864, it has been known that the eyes are liable to be attacked in acne rosacea. von Arlt recorded cases of this disease associated with conjunctivitis and shallow, round ulcers of the cornea. He recognized that treatment of the skin condition was a means of improving the state of the eyes. Many other writers subsequently reported the following ocular complications. (1) Blepharitis, (2) chalazion, (3) conjunctivitis, (4) episcleral nodules, (5) keratitis, and (6) iritis.

Blepharitis, although common, is unimportant. It merely represents an involvement of the skin of the eyelids in the process that has affected the skin of most other parts of the face. The superficial layers of the skin become desquamated, but there is none of that deep scarring which in some other varieties of blepharitis can lead to distortion of the tarsal plates, and irregularity in the growth of the eyelashes. Blepharitis in acne rosacea may remain for many years unaccompanied by any of the other ocular complications, but undoubtedly predisposes to chalazion. 
Chalazion is a common complication in the experience of many observers. Peters, who is himself an ophthalmic surgeon and a sufferer from acne rosacea, reports that he recently developed 16 small chalazia.

Conjunctivitis caused by acne rosacea differs from most other varieties of conjunctivitis in the nature of the discharge, which nearly always remains watery, even in severe cases. The main features are photophobia and profuse lacrymation, together with an engorgement of the conjunctival vessels, especially of those that supply the interpalpebral portion of the ocular conjunctiva. Mucopurulent secretion, when it does occur, may reasonably be explained by the migration of staphylococci from the neighbouring skin. These organisms were often found by Whitfield in eyes affected by acne rosacea. In the case reported by Clark, a mucopurulent conjunctivitis, which had previously resisted treatment for several months,subsided as soon as the associated rhinophyma had been treated by electrical desiccation.

Episcleral nodules or pseudo-phlyctenules are believed by Peters and others to be very characteristic of acne rosacea. They are usually situated within $5 \mathrm{~mm}$. of the limbus, and are accompanied by conjunctivitis. Imre thinks this disease should be suspected whenever phlyctenule-like nodules arise on the eyes of an adult.

Keratitis is chiefly confined to the corneal epithelium and the superficial layers of the substantia propria, where it produces greyish infiltrates and multiple ulcers. It shows a marked tendency to relapse, and is always accompanied by vascularization. The adventitious vessels are partly an extension of those which supply the ocular conjunctiva, and partly of new formation. The characteristic " looping" of the vessels has been remarked upon by Weidler. Cicatrisation following ulcers may lead to localized thinning of the cornea, with the formation of facets, whose presence has been noted by Cruise, Holloway, Bailliart and Blutel. With each successive attack the infiltration insinuates itself further towards the axial portion of the cornea, so as to interfere with clear vision. Lacarrère described the typical horse-shoe or tongueshape of the resulting opacities. In addition to these main infiltrates beginning at the periphery, numerous superficial grey dots, as figured by Butler, may be scattered at random over any part of the cornea. Duke-Elder has written of a case in which the contents of an interstitial abscess or corneal pustule had to be evacuated.

Sometimes the corneal involvement is remarkably severe. Thus Capauner witnessed the development of complete opacity in the corneae of two of his patients. Blancke and Blatt have both described a corneal ulcer with elevated, undermined edges, reminiscent of Mooren's ulcer. Keratectasia has been reported by 
Blatt and Weidler. Actual perforation of the cornea is another serious possibility exemplified by cases with adherent leucoma mentioned by Wicherkiewicz and Kuntz.

Iritis is not per se a complication of acne rosacea, but can arise from severe corneal ulceration in this disease-as indeed it may follow most other varieties of corneal ulceration. In a case of Blancke's, with bilateral iritis associated with bilateral ulceration of the cornea, one eye developed an hypopyon.

Nobody has yet convincingly explained why ocular complications arise in some cases of this disease. According to Bailliart and Blutel, they are especially to be feared whenever the face is severely affected, but Low's observations led him to the contrary conclusion that most of the ocular cases exhibited only mild facial lesions. Löwenstein failed to find any organism in corneal fragments excised from patients with acne rosacea keratitis, but succeeded four times out of seven in affecting rabbit's corneae by inoculation with such fragments. With one exception, fragments of affected skin gave negative results on similar inoculation. He attributes conjunctivitis and keratitis in the human subject to direct spread of the infection from the face by way of the eyelids. Although this would seem to be a reasonable explanation, it does not dispose of the difficulty that many cases of acne rosacea blepharitis remain for years without suffering any involvement of the conjunctiva and cornea.

Verhoeff regards the keratitis of acne rosacea as a form of neuropathic keratitis due to injurious efferent impulses passing from a. diseased Gasserian ganglion. Furthermore, he offers the same interpretation of the facial lesions, which are also situated in the area supplied by the fifth cranial nerve. To this attractive hypothesis many objections might be made. From the ophthalmological standpoint, one obvious barrier to its acceptance is the fact that the clinical appearances found in affected corneae differ profoundly from those which characterize ordinary neuropathic keratitis.

von Szily made pathological investigations on pieces of cornea excised from cases of acne rosacea keratitis. He described folliculiform accumulations of lymphocytes bordering central zones of epithelioid cells, and in late cases noticed the presence of giant cells of the foreign-body type.

\section{Treatment}

A. General.-von Arlt's observation that the ocular complications require treatment of the skin condition as well as the application of local eye remedies has been supported by many other workers. The following recognized methods of treatment, though 
primarily directed to the improvement of the face, are regarded as incidental ways of altering the eye condition.

(1) Applications to the face itself.-The use of sulphur and calamine lotions is widely supported. Sequeira praises the results of X-ray treatment. Duke-Elder irradiates the face with ultraviolet light in order to increase the good effect of similar radiation applied to the eyes.

(2) Drugs by the mouth, including arsenic (Verhoeff) and salicylates (Weidler). Dilute hydrochloric acid at meal times is recommended to counteract the hypochlorhydria, whose frequent association was mentioned above. Eastwood claims beneficial results from the use of this acid even in those who fail to show the customary deficiency on gastric analysis. It is interesting to recall the empirical use of this remedy by Stephenson many years before it was rationalized by the findings of Ryle and Barber. .

(3) Dietetic restrictions have always been popular. Total or partial abstinence from tea and alcohol are commonly advised. Eastwood recommends a low carbohydrate intake. Copious draughts of fluid before meals are said to be beneficial.

B. Local.-The usual remedies given for the affected eyelids are zinc and ichthyol ointments; for the conjunctiva, boracic lotion and powdered calomel ; for the cornea, atropine and dionine. Holocaine is used for the keratitis by Verhoeff, Holloway, and Darier. Verhoeff says the beneficial action of holocaine is the result of its paralytic effect on the sensory nerve-endings, through which medium he conceives of the disease as being conveyed to the cornea from a Gasserian lesion. Schirmer gave subconjunctival injections of saline solution. Local applications of ultra-violet light, combined with general light-baths, are recommended by DukeElder. von Szily and Greeves claim success from X-ray treatment.

Numerous operative measures have been employed, but have met with scanty support in this country. Goldsmith recorded the failure of his attempt to arrest corneal infiltration by the operation of peritomy. Excision and cauterization of recent conjunctival foci is advocated by von Szily. Bailliart and Blutel performed iridectomy. Verhoeff claims success for pericorneal neurotomy. Piriès excised a ring of conjunctiva, and filled the gap with a mucous membrane graft from the lip. Cauterization and curettage have been practised by several other continental surgeons.

\section{II.-Personal Observations}

Aetiology.-The clinical investigations here described were carried out mainly among ophthalmic out-patients at special and general hospitals, and to a less extent among out-patients attending the skin department of a general hospital. Personal notes have 
been written concerning the condition of 78 acne rosacea cases, most of whom have been re-examined at intervals over periods varying from six months to two years. In addition to my own observations, I have in many instances been able to gather information from past notes. Of the 78 patients, 65 (or 83.3 per cent.) were women; 13 (or 16.7 per cent.) were men. Their ages ranged from 28 to 67 , but most of them were between 35 and 55 years old. Sixty-one of them suffered from ocular complications, but it must be remembered that the great majority of the 78 were ophthalmic out-patients. Among 13 cases seen in a skin department none had ever suffered from ocular complications.

Enquiries into the diet and general health of the patients did not lead to the discovery of any constant group of aetiological factors apart from those of age and sex noticed above. A history of indigestion was frequently absent. Many patients denied that they had ever over-indulged in tea, alcohol, or tobacco. Some had abstained from the use of these articles for several years past, in accordance with medical advice, but without the event of a permanent cure. Dysmenorrhoea was not common among the women, but several of them thought that pregnancy or menstruation seemed either to induce or to exacerbate an attack. Two women definitely attributed the origin of the disease to domestic distress due in the one case to death and in the other to desertion of their respective husbands. It was claimed by one mana commercial traveller-that his facial rash always subsided when he went away from home, but was wont to recur on resumption of normal relationship with his wife. The impression gained from my enquiries was that most of these people enjoyed fairly good general health. In this respect my experience differs from that of several authors, in whose writings the typical acne rosacea sufferer is represented as a chronic invalid.

Ocular Complications.-As a rule the face was severely affected in those who displayed ocular complications, and the onset of a fresh attack of conjunctivitis or keratitis coincided with a return of the facial efflorescence. In two cases, however, the cornea was attacked in spite of exceedingly mild facial manifestations. One of them was, in fact, unaware of her skin trouble. With two exceptions the ocular involvement was bilateral, but the beginning of the affection in the second eye was commonly delayed until months or years after the invasion of the first eye. The first signs of the disease on the face had usually preceded the eye trouble by a considerable interval-sometimes as long as ten years.

Some degree of blepharitis with scaly desquamation was observed in all those that showed any ocular complications. In no case did the blepharitis result in any appreciable disability per se, although it may have rendered possible the extension of the disease from the 
face to the eyeball. Eleven examples of chalazion, often multiple, occurred in the series, but presented no points of distinction from ordinary chalazia.

Conjunctivitis was a prominent feature in all cases with keratitis, but seldom occurred in the absence of that complication. In a few cases I was able, on repeated examinations at short intervals, to observe corneal infiltration follow on conjunctivitis. Only once did I see a case of typical acne rosacea conjunctivitis endure for as long as a month without some involvement of the cornea becoming evident. Greyish-white nodules or pseudo-phlyctenules were seen on the ocular conjunctiva of eight eyes. Engorgement of the vessels of the ocular conjunctiva, especially in the interpalpebral region, was always a prominent feature. Photophobia and profuse lacrymation were invariably present.

Thirty-eight of the patients had corneal lesions. The first indication of a threatening keratitis is provided by the encroachment of superficial vessels from the ocular conjunctiva on to the periphery of the cornea around all or any portion of its circumference. After a varying interval one or more greyish-white infiltrates appear at some part of the corneal periphery. Superficial new vessels always accompany these infiltrates, and often form characteristic loops. They remain conspicuous even in the quiescent stages of the disease, so that a vigorous flow of circulating blood can always be demonstrated therein at any time after their development. This behaviour may be contrasted with the tendency to shrinkage shown in the quiescent stage by the new vessels which invade the cornea in some other diseases, e.g., trachoma and interstitial keratitis. The infiltrates affect the lower much more than the upper half of the cornea, and are situated chiefly in the superficial layers. With each fresh outbreak of activity they tend to spread with their accompanying vessels, further towards the axial portion of the cornea. In many cases the epithelium overlying an infiltrate sloughs off, leaving an irritable ulcer. Twenty-six of these cases have on one or more occasions needed carbolization for an ulcer. All infiltrates result in some degree of corneal opacity. In corneae which have suffered numerous attacks the main opacity is frequently horse-shoe-shaped, or wedge-shaped with the apex directed to the corneal axis. Small depressed scars forming sharply localized corneal facets were noted in seven cases. Scattered greyish-white spots, separate from the main infiltration, were commonly observed in the epithelium or in the anterior layers of the substantia propria. In five of the more severe cases a small yellow interstitial abscess or corneal pustule occurred. The deeper layers of the substantia propria were seldom affected, but in three cases a few deep adventitious vessels were found therein. During the intervals between attacks the slit-lamp was employed to 
demonstrate many of these features in greater detail. One very striking feature emphasized by the slit-lamp is the roughening of the cornea in the affected regions. The size and superficial situation of the blood-vessels, together with the irregular scars that follow on ulcers and infiltration, give rise to a haphazard series of elevations and depressions revealed by the beam of light travelling across the corneal surface.

Iritis accompanied ulceration of the cornea in eight cases, but presented no special features.

Treatment.-Dogmatic assertions concerning the results of treatment in individual cases of this disease are to be avoided on account of several possible sources of fallacy. It is necessary to emphasize that the course of the disease is frequently irregular. Long spontaneous remissions may occur. Thus in one middleaged woman, who had suffered from repeated severe corneal attacks at intervals of a few months, all manifestations ceased for a period of nearly two years, during which time she was having no treatment of any kind. Although a respite of such duration is rare, yet the possibility of it must be borne in mind, lest extravagant hopes be raised by the apparent success of a therapeutic measure in one isolated case. Good results have been claimed for different methods of treatment on inadequate evidence. No case, however neglected, remains in the acute stage for many months. Should a long remission happen to follow any attack treated in a special way, then that form of treatment is apt to receive the credit for what may well have been a coincidence. No method should be commended until it has benefited a considerable number of cases. Moreover, there is a distinct tendency on the part of acne rosacea to give a temporarily favourable response to a new method of attack. A change of treatment may work like a charm the first time it is tried. Later, when the patient has come to believe that at last a real cure has been found, another attack will obstinately resist the treatment which had promised so well. It would be safe to assume that many apparent cures in the literature were merely examples of momentary improvement. Finally, the individual patients show great variations from each other in the way that they respond to different therapeutic measures. The fact that one person has been greatly relieved by one method provides no guarantee that the same method will benefit another.

Methods Used.-Chalazion was treated by the ordinary method of incision and curettage under local anaesthesia, and requires no further consideration. Blepharitis was never severe, and merely needed a mild ointment for application to the lid margins at night, Cases with conjunctivitis nearly always, as mentioned above, went on to develop a keratitis, so that this last-named complication is for present purposes the most important. Simple remedies were 
always tried first. Irrigation with boracic or with normal saline lotion, atropine drops, and the use of dark glasses were usually prescribed, together with sulphur lotion for the skin of the face, and dilute hydrochloric acid to be taken by the mouth at meal times. These measures undoubtedly shortened the attacks in some cases, but in others were unavailing. When they failed to produce much benefit, ultra-violet light was usually employed if the patient's circumstances allowed her to make the frequent visits required for the application of this treatment. Fifteen cases of acne rosacea keratitis were treated with ultra-violet light. Nine of them derived much temporary benefit from it; three were slightly relieved; and three failed to respond favourably. The routine procedure was to give general light baths combined with local radiation of the face and cornea. 'Three cases of keratitis were treated by the application of X-rays to the cornea. This treatment appeared greatly to improve two of them, but the third was not appreciably benefited. Further observations on the results of X-ray treatment are needed before the value of this method can be correctly assessed, but the results are certainly encouraging. It possesses the distinct advantage that the number of attendances required of the patient is smaller than that which obtains in ultra-violet treatment.

The following short case histories are intended to show the variability in the clinical course of this disease, and the diversity of the results of treatment.

Case I.-H.S., a man aged 48 years, has had facial and ocular acne rosacea for over 20 years, especially during the spring and autumn. The disease readily responds to simple remedies whenever a fresh attack arises. The corneal appearances are quite typical except for the presence of a few folds of Descemet's membrane in the axial and inferior regions of the right cornea. His general health is fairly good, although he is of a neurasthenic nature.

Case II.-E.P., a healthy woman aged $5 \%$ years, eye obstinately resistant to treatment. In 1925, the facial rash having been intermittently present for ten years, both eyes began to be red and watering at intervals. Bilateral corneal ulceration arose in January, 1928. For the next six months she underwent courses of ultra-violet treatment with encouraging immediate results, but suffered a relapse in September of the same year. In spite of further ultra-violet irradiation, combined with the customary simple methods of treatment, the ulceration has repeatedly recurred. The last ulcer arose in September, 1930. On seven occasions during the last three years it has been necessary to resort to carbolization. Both corneae present numerous vascularized opacities which have begun to encroach on the pupillary area. 
Case III.-A. M., a woman aged 50 years, began to suffer from facial attacks in 1915, but has always enjoyed good general health. Since 1918 she has suffered from blepharitis. In 1925 right keratitis supervened, and led to attacks of corneal ulceration twice a year until she underwent a course of ultra-violet light early in 1928. During the last three years the facial manifestations have been milder, and there has been no further ulceration of this cornea, whose lower half now shows numerous vascularized opacities with ill-defined margins. Peripheral vessels and scattered round grey dots are present in the upper half. The left cornea has so far remained free.

Case IV.-A. H., a healthy woman aged 56 years, has had face trouble since 1927 , especially in the summer. Two years ago the right eye began to suffer from keratitis. The left eye also became involved one year ago. In January, 1930, an obstinate deep nodule invaded the right cornea near the limbus. This eye also showed multiple corneal nebulae and superficial new vessels. Pigmented deposits adhering to the anterior lens capsule after atropinisation proved the co-existence of iritis. In the left eye were four limbal phlyctenules. After a short course of simple remedies, including dilute hydrochloric acid taken internally with her meals, she rapidly improved, only to relapse two months later. Thereupon, ultra-violet treatment was started. Relief was almost instantaneous, and when she last attended in January, 1931, there had been no further outbreak.

Case V.-M. K., a healthy woman aged 34 years, began to have facial attacks in 1924. At that time a chalazion appeared. The face always seemed worse between January and March. In 1927, both eyes became involved, and were irritable during most of the following year. Between October, 1928, and June, 1929, she underwent two courses of ultra-violet treatment with great benefit. Apart from the development of another chalazion in 1929, she has had no return of eye trouble. Both corneae show peripheral vascularization around their whole circumference. Numerous small superficial opacities lie scattered over the corneae, especially in their lower halves.

Case VI.-F. K., a healthy woman aged 41 years, began to suffer with her eyes before the facial rash became evident. In 1926 she began to complain of gritty sensations in the left eye. At that time there was an encroachment of superficial vessels on the left cornea, whose surface was noticeably roughened. Several attacks of slight ulceration supervened. From July, 1927, to March, 1929, she underwent ultra-violet light treatment at intervals, but this measure did not succeed in staving off the recurrences. Later, in 
1929 , a severe corneal ulcer of the left eye had to be carbolized, and a further course of ultra-violet light was begun. At this time the affection began to involve the fellow eye, in spite of rest at a convalescent home. During 1930 there were several further outbreaks in each eye. Multiple superficial vascularized scars can be seen in each cornea. In the axial region of the left cornea is a large opacity extending as deeply as the middle layers of the substantia propria, and impregnated with numerous minute crystals.

Case VII.-E. A., a woman aged 56 years, exhibits the facial affection in a very mild form. She complains of flatulence, but is of a healthy appearance. Her left cornea became ulcerated in April, 1928. During the remainder of that year and in 1929 she sustained several other corneal invasions in each eye. Between January and May, 1930, she was given six local X-ray applications, after which she noticed the disappearance of the unpleasant burning sensation which had previously been afflicting her eyes. Up to January, 1931, there has been no further relapse.

Case VIII.-S. B., is a healthy man aged 39 years. The onset of the facial disease in 1925 coincided with the beginning of corneal involvement. For the next four years he suffered from repeated corneal ulcers, necessitating carbolization altogether five times in one or other eye. In May, 1929, a small abscess which arose near the axis of the left cornea had to be evacuated. Thereupon, X-ray treatment was instituted, but without any immediate success, because one month later he developed another corneal ulcer. Since the X-ray treatment there has been yet another relapse in each eye, but he has now remained quiescent for the last seven months. There are large, wedge-shaped, vascularized opacities in the infero-temporal quadrant of each cornea, but the typical upper peripheral vascularization is absent. In the neighbourhood of the opacities the corneae are markedly thinned.

My thanks are due to Sir John Parsons, Mr. Foster Moore, Mr. R. A. Greeves, Mr. C. B. Goulden, and Mr. W. S. DukeElder for permission to refer in detail to the above patients under their care.

\section{Conclusions}

By reason of its capacity to produce keratitis in a small proportion of cases, acne rosacea may bring about serious disability. Keratitis in this disease causes repeated attacks of pain in the eyes, and endangers clear vision. It is exceedingly difficult to cure, and may be almost impossible to relieve. If one system of treatment fails, then others should be tried, in order to shorten the attacks 
and to.increase the intervals of quiescence. A permanent cure is not claimed in any single instance. Treatment by ultra-violet light or $\mathrm{X}$-rays offers a chance of temporary improvement when simple remedies have produced no response.

\section{REFERENCES}

Bailliart et Blutel.-Arch.d'Ophtal., Vol. XXX, p. 507, 1913.

Blancke.-Dissertation. Giessen. 1905.

Blatt.-Klin. Monatsbl. f. Augenheilk., Vol. LXXX, p. 624, 1928.

Brown.-Brit. Jl. of Derm., Vol. XXXVII, p. 213, 1925.

Butler.-Illustrated Guide to Slit-Lamp, p. 27, 1927.

Capauner.-Zeitschr. f. Augenheilk., Vol. XI, p. 126, 1903.

Clark.-Urol. and Cut. Rev., Vol. XXV, p. 63, 1921.

Cruise.-Trans. Ophthal. Soc. U.K., Vol. XXVII, p. 45, 1907.

Darier.-La Clin. Ophtal., Vol. II, 1912.

Duke-Elder.-(a) Brit. Med, Jl., Vol. I, p. 894, 1926; (b) Trans. Ophthal. Soc. U.K., Vol. XLVI, p. 222, 1926 ; (c) Brit. Jl. of Ophthal., Vol. XII, p. 362, 1928 ; (d) Recent Advances in Ophthalmology, p. 234, 1929. Eastwood.-Brit. Jl. of Derm., Vol. IV, pp. 91 and 148, 1928.

Goldsmith.-Ophthalmoscope, Vol. V, p. 20, 1907.

Greeves.-Trans. Ophthal. Soc. U.K., Vol. L, 1930.

Grintschar.-Urol. and Cut. Rev., Vol. XXXVIII, p. 85; 1928.

Holloway.-Arch. of Ophthal., Vol. XXXIX, p. 321, 1910.

Imre.-Klin. Monatsbl. f. Augenheilk., Vol. LXXIII, p. 499, 1924.

Kuntz.-Dissertation. Greifswald. 1905.

Lacarrère.-Arch. de Oftal., Vol. XXII, p. 121, 1922.

Low.-Brit. Jl. of Derm., Vol. XXXIV, p. 275, 1922.

Löwenstein.-Derm. Wochenschr., Vol. LXXIX, p. 1,089, 1924.

Peters.-(a) Klin. Monatsbl. $f$. Augenheilk., Vol. XLII, p. 225, 1925; (b) Zeitschr.f. Augenheilk., Vol LXIX, p. 144, 1929.

Piriès.-Arch. d'Ophtal., Vol. XLV, p. 308, 1928.

Rulison.-Amer. Jl. Med. Sci., Vol. CLXXIV, p. 60, 1927.

Ryle and Barber.-Lancet, Vol. II, p. 1195, 1920.

Schirmer.-Zeitschr. f. Augenheilk., Vol. XV, p. 501, 1906.

Sequeira.-Diseases of the Skin, pp. 420-423, 1927.

Stephenson.-Trans. Ophthal. Soc. U.K., Vol. XXVI, p. 47, 1906.

Triebenstein.-Klin. Monatsbl. f. Augenheilk., Vol. LXVIII, p. 3, 1922.

Verhoeff-(a) Trans. Amer. Ophthal. Soc., Vol XIV, p. 98, 1915-1916; (b) Jl. Amer. Med. Assoc., Vol. LIII, p. 191, 1909.

von Arlt.-Klin. Monatsbl. f. Augenheilk., Vol. II, p. 329, 1864.

von Szily.-Klin. Monatsbl. f. Augenheilk., Vol. LXXXII, p. 577, 1929.

Weidler.-Med. Record, Vol. LXXIX, p. 204, 1911.

Wicherkiewicz-Post. Okilist., 1907. 